\title{
Species-specific effects of anticoagulants on red blood cell deformability
}

\author{
N. Nemeth ${ }^{\mathrm{a}, *}$, O.K. Baskurt ${ }^{\mathrm{b}}$, H.J. Meiselman ${ }^{\mathrm{c}}$ and I. Miko ${ }^{\mathrm{a}}$ \\ ${ }^{a}$ Medical and Health Science Center, Department of Operative Techniques and Surgical Research, \\ Institute of Surgery, University of Debrecen, Debrecen, Hungary \\ ${ }^{\mathrm{b}}$ Department of Physiology, Faculty of Medicine, Akdeniz University, Antalya, Turkey \\ ${ }^{\mathrm{c}}$ Department of Physiology and Biophysics, University of Southern California, Keck School of \\ Medicine, Los Angeles, CA, USA
}

The potassium salt of ethylene-diamine-tetraacetic acid $\left(\mathrm{K}_{3}\right.$-EDTA) is the recommended anticoagulant when blood is drawn by venipuncture for in vitro hemorheological studies [2,3,5]. However, when intravascular intervention (e.g., catheterization, cannulation, performing vascular anastomoses, etc.) is done in animal research, it is essential to use the anticoagulant heparin in cannulas and catheters and sometimes systemically (i.e., intravenously). Consequently, in certain animal experiments, heparin is both acceptable and necessary for hemorheological measurements. However, the known effects of heparin have to be considered when evaluating rheological results $[1,4]$.

An in vitro comparison of $\mathrm{K}_{3}$-EDTA versus sodium-heparin anticoagulation of blood samples has been carried out in the Research Laboratory, Department of Operative Techniques and Surgical Research, Medical and Health Science Center, University of Debrecen. In morning hours, blood was obtained in closed vacuum tubes from $\mathrm{CD}$ rats $(n=5$, females, bodyweight $300.4 \pm 30.9 \mathrm{~g})$ by cardiac puncture under anesthesia with pentobarbital (60 mg/bwkg, i.p.), and from beagle dogs $(n=5$, females, bodyweight: $12.0 \pm 2.13 \mathrm{~kg}$ ) by cephalic vein puncture. Anticoagulant levels were $1.5 \mathrm{mg} / \mathrm{ml} \mathrm{K}_{3}$-EDTA and $10 \mathrm{U} / \mathrm{ml}$ for sodium-heparin; each anticoagulant was contained in the vacuum tubes. All blood samples were stored at room temperature until studied and all measurements completed within one hour following blood sampling. The blood samples were tested as-drawn for white and red blood cell counts, platelet count, hematocrit, total and intracellular hemoglobin concentration, mean cell volume and intracellular hemoglobin content (Sysmex F-800 microcell counter, TOA Medical Electronics Corp., Japan). RBC deformability in these samples was measured using a slit flow ektacytometer (RheoScan-D 200, Sewon Meditech Inc., South-Korea) [6]; this device subjects RBC to various levels of fluid shear stress and calculates an elongation index (EI) which increases with cell deformation.

As anticipated, platelet counts were significantly lower in the heparin samples (data not shown); none of the other hematological parameters exhibited important differences. However, the effects of the two

\footnotetext{
* Corresponding author: Norbert Nemeth, MD, PhD, Department of Operative Techniques and Surgical Research, Medical and Health Science Centre, University of Debrecen, Nagyerdei krt. 98, H-4032 Debrecen, Hungary. Tel./Fax: +36 52 416 915; E-mail: nemeth@med.unideb.hu.
} 

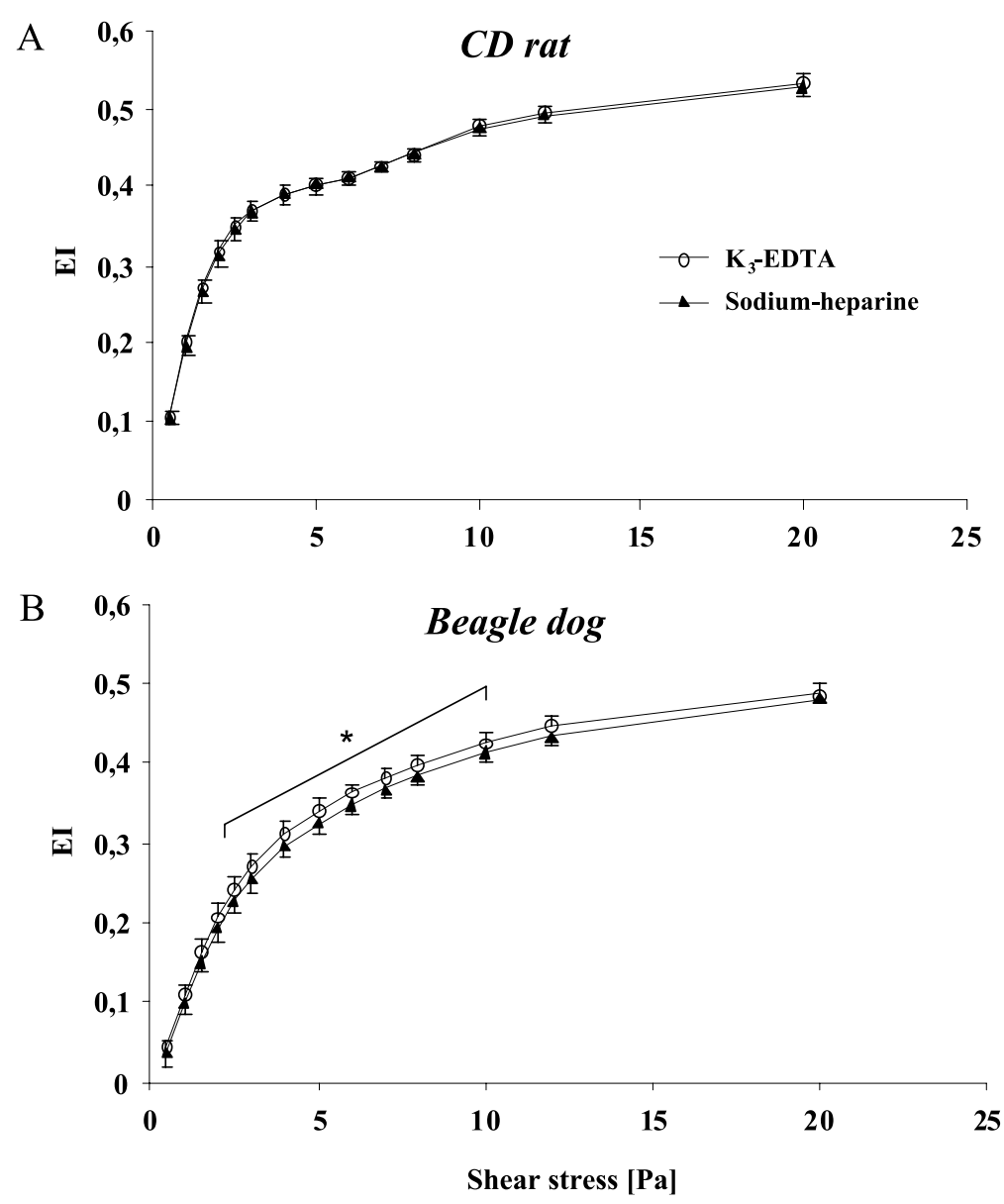

Fig. 1. Elongation index (EI) values as a function of shear stress $(\mathrm{Pa})$ measured for blood samples anticoagulated with $\mathrm{K}_{3}$-EDTA or sodium-heparin for $\mathrm{CD}$ rats (A) and beagle dogs (B). Data are mean $\pm \mathrm{SD}, n=5,{ }^{*} p<0.05$ for $\mathrm{K}_{3}$-EDTA vs. sodium-heparin.

anticoagulants on RBC deformability were species-specific: (1) in rats the EI values were identical in EDTA and heparinized blood samples (Fig. 1A); (2) in beagle dogs elongation index values were significantly lower in the heparin samples over a shear stress range of $2.5-10 \mathrm{~Pa}(p<0.05$, Fig. 1B).

We believe that these data indicate the need to be aware of potential hemorheological effects when interpreting studies in which heparin is used as a systemic anticoagulant versus studies in which nonheparinized blood is drawn into EDTA. Failure to recognize these differences could lead to an incorrect interpretation of experimental data.

Red blood cell deformability data cannot be compared across different sampling and handling conditions, and thus the adequate control group is essential in the experiment setup.

\section{Acknowledgement}

Supported by Hungarian Research Fund (OTKA) Nr. F-68323; Turkish-Hungarian Bilateral Program Nr. BILAT TR-03/2006. 


\section{References}

[1] V. Bartoli, B. Albanese, P.G. Manescalchi, L. Mannini and G. Pasquini, Influence of blood storage conditions and anticoagulants on results of blood cell filtration test, Clin. Hemorheol. 6 (1986), 137-149.

[2] O.K. Baskurt, M. Boynard, G.C. Cokelet, P. Connes, B.M. Cooke, S. Forconi, M.R. Hardeman, F. Jung, F. Liao, H.J. Meiselman, G. Nash, N. Nemeth, B. Neu, B. Sandhagen, S. Shin, G. Thurston and J.L. Wautier, New guidelines for hemorheological laboratory techniques, Clin. Hemorheol. Microcirc. 42(2) (2009), 75-97.

[3] M.R. Hardeman, P.T. Goedhart and S. Shin, Methods in hemorheology, in: Handbook of Hemorheology and Hemodynamics, O.K. Baskurt, M.R. Hardeman, M.W. Rampling and H.J. Meiselman, eds, IOS Press, Amsterdam, The Netherlands, 2007, pp. 242-266.

[4] L. Heilmann, W. Rath, K. Pollow and R.L. Bick, The rheological changes after cesarean section: The influence of low molecular weight or unfractionated heparin on the rheological properties of blood, Clin. Hemorheol. Microcirc. 37 (2007), 211-218.

[5] ICSH Expert Panel on Blood Rheology, Guidelines for measurement of blood viscosity and erythrocyte deformability, Clin. Hemorheol. 6 (1986), 439-453.

[6] S. Shin, Y. Ku, M.S. Park and J.S. Suh, Slit-flow ektacytometry: laser diffraction in a slit rheometer, Cytometry Part B (Clin. Cytometry) 65 (2005), 6-13. 